\title{
O gênero textual biografia como eixo organizador de uma proposta de intervenção didática na educação básica
}

\author{
El género textual biografía como eje organizador de una \\ propuesta de intervención didáctica en la educación básica
}

\author{
The textual genre biography as organizing axis of a \\ proposal for didactic intervention in basic education
}

\author{
Marilúcia dos Santos Domingos Striquer ${ }^{1}$ \\ Margarina Paulino de Cerqueira Pinto ${ }^{2}$
}

\begin{abstract}
RESUMO: Este artigo apresenta o processo de elaboração e de implementação de um projeto de intervenção pedagógica destinado ao desenvolvimento da produção textual dos alunos do $6^{\circ}$ ano do ensino fundamental, tendo como eixo organizador o gênero textual biografia. $O$ arcabouço teórico se constitui dos pressupostos da vertente didática do Interacionismo Sociodiscursivo. Os resultados demonstram como a modelização contribui para que as características do gênero pudessem ser selecionadas pelo professor como objeto de ensino; e como o aporte teóricometodológico possibilitou que a cultura local pudesse ser conhecida e motivadora para os alunos, bem como para o aprimoramento da prática da produção de texto dos alunos, exemplificada em um exemplar do gênero produzido pelos alunos.
\end{abstract}

PALAVRAS-CHAVE: Gêneros textuais. Biografia. Modelização. Sequência didática. Interacionismo sociodiscursivo.

RESUMEN: Este artículo presenta el proceso de elaboración y de implementación de un proyecto de intervención pedagógica destinado al desarrollo de la producción textual de los estudiantes del $6^{\circ}$ año de la enseñanza fundamental, teniendo como eje organizador el género textual biografía. El marco teórico se constituye de los presupuestos de la vertiente didáctica del Interaccionismo Sociodiscursivo. Los resultados demuestran cómo la modelización contribuye para que las características del

${ }^{1}$ Doutora em Estudos da Linguagem. Professora e pesquisadora da Universidade Estadual do Norte do Paraná (UENP). marilucia@uenp.edu.br

2 Professora da Secretaria de Educação do Estado do Paraná e professora da Prefeitura Municipal de Ourinhos-SP. Graduada e especialista em Letras: Português, Literatura e Espanhol. Graduada em Pedagogia. margotcerqueira@hotmail.com 
género puedan ser seleccionadas por el maestro como objeto de enseñanza; y como el aporte teórico-metodológico posibilitó que la cultura local pudiera ser conocida y motivadora para los estudiantes, así como para la mejora de la práctica de la producción de texto de los estudiantes, ejemplificada en un ejemplar del género producido por los estudiantes.

PALABRAS CLAVE: Géneros textuales. Biografía. Modelización. Secuencia didáctica. Interaccionismo sociodiscursivo.

ABSTRACT: This article presents the process of elaboration and implementation of a project of pedagogical intervention destined to the development of the textual production of students of the 6th year of elementary education, having as organizing axis the textual genre biography. The theoretical framework consists on the presuppositions of the didactic strand of Socio-discursive Interactionism. The results demonstrate how modeling contributes to the genre characteristics could be selected by the teacher as a teaching object; and how the theoretical-methodological approach allowed that the local culture could be known and motivating for the students, as well as for the improvement of students' text production practice, exemplified in a copy of the genre produced by the students.

KEYWORDS: Textual genres. Biography. Modeling. Didactic sequence. Sociodiscursive interactionism.

\section{Introdução}

Este trabalho apresenta, em síntese, o processo de elaboração e os resultados da implementação de um projeto de intervenção pedagógica realizado com alunos do $6^{\circ}$ ano do ensino fundamental, parte integrante das atividades desenvolvidas pelas autoras na participação no Programa de Desenvolvimento da Educação (PDE), da Secretaria de Educação Básica do Estado do Paraná, bem como vincula-se ao projeto de pesquisa "Gêneros discursivos/textuais: dos documentos prescritivos à sala de aula"3 (UENP).

O objetivo do projeto de intervenção foi o de desenvolver capacidades de linguagem de alunos do $6^{\circ}$ ano do ensino fundamental do Colégio Estadual Luiz Setti, da cidade de Jacarezinho, estado do Paraná, para a produção escrita do gênero textual biografia. Aliado a esse objetivo maior, a intenção foi

3 O referido projeto de pesquisa é desenvolvido e subsidiado pela Fundação Araucária do Paraná, pela Bolsa de Produtividade em Pesquisa, projeto "Escrita, revisão e reescrita na formação docente" (Prot. 49372). 
também a de contribuir com a disseminação e a preservação da cultura literária da cidade de Jacarezinho.

A justificativa da delimitação para o trabalho com gêneros textuais se estabeleceu, sobretudo, porque a Diretriz Curricular Estadual de Língua Portuguesa (DCE) (PARANÁ, 2008, p. 89) orienta que para o ensino com a língua o conteúdo estruturante "é o discurso como prática social" (PARANÁ, 2008, p. 89), e a partir dessa perspectiva advém os conteúdos básicos: "os gêneros discursivos a serem trabalhados nas práticas discursivas" (PARANÁ, 2008, p. 90). A fim do desenvolvimento das práticas de leitura, da oralidade, da escrita e da análise linguística dos alunos, orienta o documento que o aluno seja colocado em contato com diversos gêneros, de diferentes esferas sociais, destarte, sendo de responsabilidade do professor a seleção dos gêneros e o grau de complexidade a constituir o trabalho conforme cada ano escolar. Assim, entre os inúmeros gêneros existentes, escolhemos como eixo organizador de nosso projeto de intervenção pedagógica, a biografia.

Já a motivação para elaboração de um projeto que envolvesse o trabalho com o desenvolvimento e o aprimoramento das capacidades de linguagem para a leitura e a produção de textos dos alunos, buscando aproximá-los da cultura literária da própria cidade nasceu de nossa experiência docente ${ }^{4}$ em salas de aulas de $6^{\circ}$ anos no ensino fundamental de colégios da cidade de Jacarezinho, onde observamos que muitos alunos apresentam alguns déficits em relação à pratica de leitura, de produção de texto e de análise linguística. Contudo, o problema maior é que esses alunos, de uma cidade pequena, do interior do estado, têm pouco acesso à cultura artística e literária. A cidade não tem cinema, poucas apresentações de peças de teatro e quando isso acontece, geralmente, são eventos de valores não muito acessíveis a todos, uma

\footnotetext{
${ }^{4}$ A primeira autora é a professora da educação básica que elaborou e implementou o projeto de intervenção em decorrência de sua participação no PDE (2016-2017). A segunda autora é professora do ensino superior, orientadora de todo o processo de elaboração e implementação do projeto.
} 
biblioteca municipal com acervo relativamente antigo. Às vezes, os alunos têm contato apenas com livros da biblioteca do Colégio.

Em contraponto, Jacarezinho é uma cidade de tradicionais autores de livros, são: professores, bancários, advogados, comerciantes, pessoas que nasceram na comunidade local ou que vivem na cidade por alguns anos e que são conhecidos por seus escritos: poemas, contos, livro infantil, livros de autoajuda, obras que contam a história de Jacarezinho, dentre outras. Muitas dessas obras são publicadas por pequenas gráficas comerciais e custeadas pelos próprios autores, não tendo, portanto, muita divulgação, nem mesmo local. Algumas delas apenas fazem parte do acervo do Serviço Social do Comércio (SESC) de Jacarezinho, outras, por meio de doação do autor, estão na biblioteca do município e algumas nas bibliotecas das escolas e colégios da cidade. Em decorrência, conforme diagnóstico que realizamos antes da elaboração do projeto de intervenção, poucos alunos conhecem os autores jacarezinhenses e suas obras.

Diante dessas intenções e situações, construímos algumas hipóteses: conhecer e encontrar pessoalmente os escritores jacarezinhenses e suas obras poderia ser um elemento motivacional para o desenvolvimento das práticas de leitura e escrita dos alunos da educação básica, uma vez que tanto a história de vida dos autores como o processo de criação de escritos; o interesse pela história da comunidade local tematizadas nos textos, seria uma adequada ferramenta para despertar o interesse dos alunos para às práticas discursivas da leitura e da escrita de textos. Logo, construímos e implementamos o projeto de intervenção, e este artigo tem, portanto, o objetivo de apresentar o processo e os resultados da implementação. 0 arcabouço teórico principal que sustentou 0 trabalho constitui-se dos preceitos do Interacionismo Sociodiscursivo.

A organização deste artigo se estabelece na apresentação, na próxima seção, dos fundamentos teórico-metodológicos que sustentaram a elaboração e 
implementação do projeto; em seguida, uma modelização do gênero textual biografia; a sequência didática e relatos de como aconteceu sua implementação; e alguns considerações finais.

\section{Fundamentação Teórico-metodológica}

Os gêneros são entidades responsáveis pela articulação das nossas falas cotidianas ou formais. Ou seja, falamos e escrevemos sempre e tão somente por meio de gêneros. Por exemplo, desde um bom dia que damos pela manhã a um de nossos familiares, até uma opinião sobre um fato mais complexo, objeto de trabalho com os nossos alunos, são gêneros materializados em textos. Portanto, em todas as nossas atividades, conforme Bakhtin (2003), utilizamos diversos gêneros discursivos. Nas palavras de Rojo e Barbosa (2015, p. 17), "os gêneros discursivos permeiam nossa vida diária e organizam nossa comunicação. Nós os conhecemos e utilizamos sem nos dar conta disso. Mas, geralmente, se sabemos utilizá-los, conseguimos nomeá-los".

Ainda de acordo com as autoras, para compreendermos com maior amplitude os gêneros discursivos faz-se necessário entendermos o que são as esferas sociais (BAKHTIN, 2003). De acordo com o estudioso, a utilização da língua, quer seja a oral ou a escrita, está relacionada à participação dos homens em esferas/campos, isto é, em situações comunicativas específicas. Para exemplificar, podemos citar a esfera escolar, a midiática, a literária/artística, dentre outras, em cada uma delas, atividades são criadas e estabilizadas por seus integrantes, como, a exposição de trabalhos de forma oral; a realização de uma avaliação de conteúdo, que acontecem na escola; a atividade de produzir e publicar uma notícia, na esfera jornalística. Assim, cada esfera e cada uma das práticas lá instituídas geram gêneros. Nas palavras de Bakhtin (2003, p. 64), as esferas organizam seus "tipos relativamente estáveis de enunciados, os quais denominamos gêneros do discurso". 
Portanto, para participação em uma situação específica e em uma atividade que está vinculada àquela situação é preciso que o indivíduo saiba interpretar e/ou produzir gêneros que estão, por sua vez, condicionados e estabilizados dentro desses aspectos. A explicação de Bakhtin (2003) é que os gêneros refletem o campo e a atividade nos três elementos que formam cada um dos gêneros existentes: o conteúdo temático, o estilo e a construção composicional.

Conforme esclarecem Rojo e Barbosa (2015, p. 65),

\begin{abstract}
Diferentes modos de vida e circunstâncias ligadas às diversas esferas/campos de comunicação, por sua vez relacionadas com os vários tipos de atividade humana e determinadas, em última instância, pela organização econômica da sociedade, gerariam tipos temáticos, composicionais e estilísticos de enunciados/textos relativamente estáveis - os gêneros.
\end{abstract}

O tema, segundo a abordagem bakhtiniana, perpassa o conteúdo, 0 assunto ou o tópico principal de um texto. Contudo, o tema é sempre considerado a partir da apreciação de valor que o produtor do texto lhe confere, a valoração que pode o destinatário do texto ter, na consideração ainda de qual é o espaço e tempo histórico da produção do texto. A construção composicional diz respeito à estrutura formal textual: a biografia é um texto, geralmente, em prosa; a extensão depende do veículo de circulação; a sequência é a do relatar acontecimentos vividos. Já o estilo é o emprego das escolhas lexicais, sintáticas, linguísticas que utilizamos para falar o que pretendemos, ou seja, nesse elemento estão envolvidos todos os aspectos gramaticais que organizam a textualidade. Na biografia há o predomínio da terceira pessoa do discurso; os verbos se encontram no pretérito perfeito do indicativo ou no presente do indicativo, presente histórico.

Corroborando com as colocações de Rojo e Barbosa (2015), os Parâmetros Curriculares Nacionais (PCNs) (BRASIL, 1997), também apresentam uma definição dos três elementos 
Os vários gêneros existentes, por sua vez, constituem formas relativamente estáveis de enunciados, disponíveis na cultura, caracterizados por três elementos: conteúdo temático, estilo e construção composicional. Pode-se ainda afirmar que a noção de gêneros refere-se a "famílias" de textos que compartilham algumas características comuns, embora heterogêneas, como visão geral da ação à qual o texto se articula, tipo de suporte comunicativo, extensão, grau de literariedade, por exemplo, existindo em número quase ilimitado. (BRASIL, 1997, p. 23).

Assim, segundo esse documento, quando lemos um texto que começa, por exemplo, com a expressão "era uma vez", já sabemos previamente que se trata, geralmente, de um conto; ou quando ouvimos a expressão "senhoras e senhores", ficamos na expectativa de ouvir um discurso público ou ainda uma apresentação de um espetáculo.

A partir desses pressupostos teóricos, para que pudéssemos conhecer os elementos que caracterizam a biografia, a fim da construção de uma sequência didática e de material de trabalho para a sala de aula, conforme orienta a vertente didática do Interacionismo Sociodiscursivo (DOLZ; NOVERRAZ; SCHNEUWLY, 2004; DOLZ; SCHNEUWLY, 2004), primeiro realizamos uma pesquisa bibliográfica sobre as definições de especialista a respeito do gênero e depois elaboramos uma modelização do gênero a partir da ferramenta Dispositivo Didático de Gênero proposto por Barros (2012).

A respeito do Dispositivo Didático de Gêneros, a ferramenta consiste em uma tabela composta por uma série de perguntas que abrangem desde os elementos que formam o contexto sóciocomunicativo de um gênero: a esfera, a atividade ou prática social de linguagem, a finalidade e o valor do gênero, até os elementos que constituem o contexto de produção (o conteúdo temático, os interlocutores da interação, o espaço e tempo da produção) e sua arquitetura interna (os elementos que formam a construção composicional e o estilo do gênero) (BAKHTIN, 2003). A seguir apresentamos o dispositivo didático de Barros (2012), adaptado, visando expor apenas as questões que estavam diretamente ligadas ao gênero biografia: 
O gênero textual biografia como eixo organizador de uma proposta de intervenção didática na educação básica

Quadro 1 - Dispositivo didático para modelização do gênero

Perguntas para direcionar a modelização do gênero

A qual prática social o gênero está vinculado? É um gênero oral ou escrito? A qual esfera de comunicação pertence (jornalística, religiosa, publicitária, etc.)? Quais as características gerais dessa esfera? Quem produz esse gênero (emissor)? Para quem se dirige (destinatário)? Qual o papel discursivo do emissor? Qual o papel discursivo do destinatário? Com que finalidade/objetivo produz o texto? Sobre o quê (tema) os textos desse gênero tratam? Qual é a relação estabelecida entre o produtor e o destinatário? Comercial? Afetiva? Qual o valor desse gênero na sociedade? Qual o suporte? Qual o meio de circulação (onde o gênero circula)?

Qual o tipo de discurso? Do expor? Do narrar? É um narrar ficcional? É um narrar acontecimentos vividos (relato)? Como é a estrutura geral do texto? Qual é a sua cara? Como ele se configura? É dividido em partes? Tem título/subtítulo? É assinado? Qual sua extensão aproximada? Acompanha fotos/figuras? Quais as características gerais? Como são organizados os conteúdos no texto? Em forma de lista? Versos? Prosa? Qual o tipo de sequência predominante? Sequência narrativa? Descritiva? Explicativa? Argumentativa? Dialogal? Injuntiva?

Como são feitas as retomadas textuais? Como é feita a coesão verbal? Quais os tipos de conectivo usados: lógico (mas, portanto, assim, dessa forma, etc.)? Temporal (era uma vez, um dia, depois, amanhã, etc.)? Espacial (lá, aqui, no bosque, etc.)? Qual a variedade linguística privilegiada? Como se dá a escolha lexical? Há mais substantivos concretos? Abstratos? Há muitos adjetivos? Como são mobilizados os sinais de pontuação no texto? Quais são os mais usados? E com qual finalidade? Que vozes são frequentes no texto? Do autor? Sociais? De personagens? Como é dada a voz aos personagens (ficcionais ou não) do texto? Há mobilização de discurso direto? Indireto? Quais processos de modalização discursiva são mais frequentes? Há a mobilização de elementos paratextuais (quadros, imagens, cores...) ou supratextuais (títulos, subtítulos, sublinhados...)?

Fonte: adaptado de Barros (2012, p. 20).

\section{A modelização do gênero textual biografia}

De acordo com Mareco e Alfena (2012), o surgimento da biografia aconteceu em época de crise, na sociedade greco-romana, devido à necessidade do registro dos fatos ocorridos na vida das pessoas que por algum motivo se destacavam. Assim, o gênero nasceu da intenção de destacar e divulgar os feitos de um indivíduo que se sobressaiu frente aos demais em uma sociedade. Contudo, naquela época, e durante muitos séculos, a inquietude era apresentar histórias de vida exemplificadoras, mais do que a verdadeira história do biografado.

O que ocorreu foi que a biografia, de acordo com Mareco e Alfena (2012, p. 78), "veio a busca pela individualidade, busca que estará sempre sujeita às condições sócio-históricas de sua produção". Dessa forma, dependendo do 
momento histórico, o biografado é um herói, um escritor, um santo, um beato, um religioso, etc.

$\mathrm{Na}$ atualidade, com os avanços científicos e tecnológicos, a biografia passa a caracterizar-se, segundo as autoras, pela "objetividade" e pela "isenção" necessárias pela interpelação científica. Frente o tempo cronometrado para tudo, a pressa que configura o momento contemporâneo, Carino (1999 apud MARECO; ALFENA, 2012, p. 79), explica que "quando não há tempo para que o homem se realize em uma vida, através de seus feitos e palavras, talvez esteja se tornando imprescindível o relato sobre vidas vividas, que só se mostram realmente completas em sua recriação biográfica". Assim, a biografia, atualmente, se origina e circula em diferentes esferas sociais, exemplos: na esfera escolar, na midiática, na esfera jornalística, na literária.

Para respondermos aos questionamentos que formam o dispositivo didático, recolhemos, segundo orientação do ISD e de Barros (2012), um conjunto de exemplares do gênero biografia. São cinco biografias de escritores brasileiros cujas obras são recomendadas por materiais didáticos e paradidáticos para o trabalho no $6^{\circ}$ ano do Ensino Fundamental a biografia de: Pedro Bandeira (MOREIRA, 2017), Monteiro Lobato (FRAZÃO, 2019), Ziraldo Alves Pinto (ZIRALDO..., 2005), Luis Fernando Veríssimo (LUIS..., 2005) e Mário Quintana (MÁRIO..., 2019). Os resultados apresentamos em seguida.

A prática social de linguagem manifestada no gênero é a de divulgar, popularizar, fazer conhecer, por meio de um relato, a história de vida de uma determinada pessoa por seus feitos relevantes para um grupo de pessoas ou para uma sociedade. E pertence à esfera literária, porque neste trabalho nosso intuito é que os textos sejam instrumentos de disseminação da cultura literária local; os exemplares que formam nosso corpus se enquadram no universo da literatura diante dos autores biografados nesses textos. Contudo nosso corpus também está inserido na esfera na esfera midiática/comercial: os sítios InfoEscola, Sua Pesquisa, o UOL Educação, veículos de comunicação virtual 
voltados a assuntos educacionais, pesquisas escolares e acadêmicas/científicas sobre obras literárias nacionais e seus autores, e o sítio E-biografias que divulga mais biografias de personalidades do Brasil e do mundo de diversas áreas, prestando-se assim a pesquisas educacionais/científicas e de conhecimentos gerais. Porém, mesmo sem fins lucrativos, quando o caso, esses sítios acabam promovendo o interesse ou necessidade de seus destinatários de comprar as biografias ou obras dos autores biografados ou as que a eles se relacionam.

A pessoa física que escreve a biografia, chamado de biógrafo, assume o papel de um cidadão que deseja que a vida do biografado se torne conhecida e ou é um jornalista, escritor que tem interesses comerciais. Em nosso projeto de intervenção, os alunos assumiram o papel de biógrafos de alguns dos escritores jacarezinhenses, com o objetivo de conhecer o processo criativo dos escritores, sua vida e obra (o intuito das professoras era o de motivar o desenvolvimento das práticas de leitura e produção de textos dos alunos) e de divulgar ainda mais esses autores e suas obras.

O destinatário do gênero pode ser um estudante, um pesquisador ou um cidadão com certo nível cultural que queira ou precise conhecer a biografia de uma determinada personalidade. Os destinatários imediatos dos textos produzidos pelos alunos do $6^{\circ}$ ano serão a comunidade escolar e a população de Jacarezinho que se interessa pela cultura local.

Há biografias publicadas em sites da internet, como é o caso de nossos cinco exemplares; e também em livros, jornais, revistas. No projeto, os alunos participantes do projeto publicaram seus textos em uma coletânea em formato de livro. O gênero, portanto, circula nas escolas, nos jornais, em sites, em revistas, ou seja, na sociedade de forma geral. E a coletânea de nossos alunos será registrada no Colégio Estadual Luiz Setti, na comunidade local, por meio do acervo das bibliotecas.

A temática se relaciona à história de vida do biografado, enfatizando as obras produzidas por ele. Por isso, a relação entre enunciador e o destinatário 
pode ser de ordem afetiva, pois o biógrafo pode realizar sua tarefa movido pela admiração à história de vida e /ou pelas obras produzidas pelo biografado. Mas também pode ter um caráter comercial, como posto. Em nosso projeto, a busca é de que os alunos se envolvam com a história de vida e com as obras dos biografados, desenvolvendo por eles, então, afeto, no sentido de admiração e respeito.

Quanto aos elementos que formam a construção composicional, segundo Bakhtin (2003), e que Barros (2012) insere como características discursivolinguísticas do gênero, a biografia é da ordem do relatar, pois trata de acontecimentos vividos - com uso de sequências narrativa em predominância , mas aparecem também a descritiva, explicativa e argumentativa (entremeadas e combinadas) para a organização e progressão textual (DOLZ; SCHNEUWLY, 2004). O texto é organizado na terceira pessoa do singular, não, necessariamente, explicitando o tempo/espaço de produção.

Esquematicamente, o plano geral pode ser apresentado da seguinte maneira: 1) título: nome do biografado, 2) Texto introdutório: geralmente faz referência aos familiares, local e data de nascimento do biografado, campo de atuação profissional, ou seja, a vida pessoal, formação escolar/acadêmica e profissional, 3) relato em ordem cronológica de acordo com as atividades desenvolvidas ao longo da vida do biografado; vale salientar que nas cinco biografias analisadas há a data de publicação das obras, com seus respectivos títulos.

Sobre o estilo (BAKHTIN, 2003) ou elementos linguísticos (BARROS, 2012), são utilizadas muitas retomadas nominais e também são frequentes o mecanismo da coesão lexical por sinônimos. 0 tempo verbal predominante é o pretérito perfeito do indicativo, porém há também o presente histórico, isto é, o biógrafo relata os acontecimentos passados como se presenciasse as cenas; são utilizados mais verbos de ação. Os tipos de conectivos usados são temporais e espaciais, a variedade linguística privilegiada é mais informal; há 
respeito pela norma padrão da língua, o texto não apresenta gírias, mas uma escolha mais livre do léxico e sintaxe que se relaciona ao assunto da biografia. Há mais substantivos concretos, verbos de ação e apresenta poucos adjetivos. O tom dado ao texto é mais objetivo. A instância geral da enunciação se faz ouvir a voz do biógrafo. Há mobilização de elementos paratextuais: foto colorida do biografado, acompanhada de uma legenda; há também a presença título (elemento supratextual). Esses recursos auxiliam na construção do sentido do texto.

A partir de conhecidas essas características da biografia, elaboramos uma sequência didática que resultou em um Material Didático-Pedagógico que nos auxiliou na implementação do projeto. Na próxima seção, expomos as etapas da sequência e nossas ações didáticas de implementação do projeto.

\section{A sequência didática e sua implementação}

O projeto foi implementado em uma sala de aula de $6^{\circ}$ ano do Ensino Fundamental, do Colégio Estadual Luiz Setti. A turma era formada por 28 alunos, na faixa-etária entre 10 a 14 anos.

De acordo com Dolz, Noverraz e Schneuwly (2004), uma sequência didática inicia-se com apresentação, pelo professor, de um problema social de comunicação e uma abordagem às características gerais do gênero que será tomado como conteúdo de ensino e aprendizagem. Dessa forma, a primeira atividade realizada, em sala de aula, foi uma roda de conversa com os alunos sobre algumas pessoas têm sua vida registrado em livros e textos, o porquê de as pessoas permitirem a publicação de sua história de vida, quem são esses biografados e seus biógrafos, qual a experiência dos alunos com a biografia: se conhecem, tiveram contato.

A maioria dos alunos revelou já ter contato com o gênero, contudo com histórias de vida de escritores da literatura infanto-juvenil. Então, apresentamos 
à classe vários livros dos escritores de Jacarezinho, um pouco da história de vida, das obras de cada um deles, da importância que essas pessoas têm para a cultura da comunidade local. No momento da elaboração do projeto já tínhamos eleito alguns dos escritores locais para o desenvolvimento do trabalho, são eles: José Lázaro Boberg, Celso Antônio Rossi, Geraldo Silva, Selma Camargo Foggiato, José Augusto Coppi.

Na sequência das ações, expomos nossa intenção de proporcionar que os alunos conhecessem alguns escritores da cidade, pudessem entrevistá-los, a fim da produção de um livro com a biografia dessas pessoas de grande importância cultural para a cidade de Jacarezinho. Os alunos entenderam que ao biografar os escritores, além de aprimorar suas capacidades de linguagem para produção de textos escritos, estariam realizando um trabalho de preservação e disseminação da cultural local.

Assim, em diversas oficinas os elementos característicos do gênero foram tomados como objeto de ensino e aprendizagem por meio de uma variedade de atividades. Destacamos aqui a organização dada para apresentação do primeiro exemplar do gênero aos alunos, uma biografia produzida pela professora Margarida sobre um dos escritores de Jacarezinho, o Sr Blás Peña Lupiañes (PINTO, 2016). Também para o trabalho com a ampla compreensão das especificidades da biografia, um exemplar do gênero autobiografia foi abordado, este produzido pelo Sr. Lupiañes.

A partir do primeiro exemplar os elementos que formam a esfera social/campo da atividade (BAKHTIN, 2003) e a prática social de linguagem manifestada pelo gênero (BARROS, 2012) foram abordados, assim como os aspectos do contexto de produção: emissor físico e social, destinatários, momento e lugar de produção, tema; suporte e veículo. Realizamos aqui uma breve apresentação de algumas das perguntas que formaram uma das atividades do caderno pedagógico utilizado (PINTO, 2016): 
7. Caros alunos, a palavra biografia é formada a partir de dois termos gregos: bios (vida) + graphein (escrever). Assim podemos compreender que quando lemos uma biografia, vamos conhecer a história de vida de determinada pessoa. Pela leitura do texto, por que Blás Peña Lupiañes foi biografado?

10. Escreva $V$ (verdadeiro) e $F$ (falso) para as afirmativas abaixo, referentes ao gênero biografia.

$A-($ ) esse gênero textual objetiva divulgar a história de vida de uma determinada pessoa que se destaca na sociedade.

B - ( ) auxilia no desenvolvimento da leitura e da escrita dos alunos.

C - ( ) somente nos livros escolares que se encontra esse gênero textual.

D - ( ) as biografias sempre são iniciadas com a expressão "Era uma vez...", fazendo com que o leitor saia do mundo real e entre no faz de conta.

\section{Quem pode ser um biógrafo?}

16. Pense na seguinte situação: além da biografia que estamos estudando, você precisará trazer para nossa aula de leitura outro texto do mesmo gênero, onde você poderá pesquisar? Ou seja, onde encontramos biografias?

Para as atividades com as características discursivas e linguísticodiscursivas específicas do gênero, utilizamos outros exemplares do gênero, entre eles duas biografias de autores cuja obras são, geralmente, conhecidas dos sextos anos: a de Ziraldo Alves Pinto e a de Monteiro Lobato. Muitos alunos mostram não lembrarem dos autores na citação aos nomes, somente quando referenciado as obras Sítio do Pica-Pau Amarelo e $O$ menino Maluquinho é que manifestaram familiaridade.

Em destaque para a abordagem à organização do conteúdo temático por meio da sequência tipológica em predominância, a narrativa, trabalhamos com mais dois textos de gêneros diferentes, o poema Charrete do vô Roque, de André Guilherme de Almeida, e o conto $A$ pipa que chegou no céu, de José Augusto Coppi (que é um dos escritores biografados pelos alunos). As questões encaminham a compreensão dos alunos a respeito por meio da comparação entre as estruturas formais de gêneros distintos.

Importante ainda expor que a maior dificuldade que os alunos tiveram foi com a compreensão a respeito da função do tempo verbal em 
predominância como mecanismo de textualidade que contribui para a construção do sentido do texto, o pretérito perfeito do indicativo. Diante do fato, vários outros exercícios tiveram que ser elaborados, além dos que formaram o caderno pedagógico.

Trabalhados os elementos que formam a biografia, em suas características sóciocomunicativas, discursivos e linguístico-discursivas, partimos para atividades com o gênero discursivo/textual entrevista. $O$ objeto foi que os alunos construíssem um questionário orientador para entrevistar os escritores que seriam por eles biografados. Também foi elaborado um planejamento e cronograma de execução de eventos, em sala de aula, para recepção e entrevista dos escritos jacarezinhenses.

A maioria das entrevistas foram realizadas na sala de aula, em visita do escritor ao colégio, algumas, por problemas de agenda dos convidados, foram realizadas em locais que melhor atendesse a eles. Todas as entrevistas foram gravadas em áudio e vídeo e depois transcritas pelos alunos.

A primeira escritora recebida foi a senhora Selma Camargo Foggiato. A Sra. Selma contou sua história de vida aos alunos e dramatizou algumas de suas obras e de alguns clássicos da literatura infanto-juvenil. Um grupo de quatro alunos realizou a entrevista com a escritora.

O senhor Geraldo Silva foi o segundo entrevistado, trouxe muitos livros e materiais que contam a história da escrita; apresentou uma retrospectiva desde Johann Gutenberg até a contemporaneidade. Aos 90 anos de idade, dramatizou alguns textos, contou histórias divertidas sobre sua infância e juventude e relatou algumas das histórias que compõem suas obras. Outros quatro discentes entrevistaram o escritor.

O terceiro entrevistado foi o professor José Lázaro Boberg; essa entrevista foi realizada por mais quatro alunos, fora da sala de aula, em local determinado pelo escritor, devido a algumas necessidades particulares dele. 0 quarto foi o Sr. Celso Antônio Rossi, entrevistado na biblioteca do colégio, por 
mais quatro alunos; dentre os vários assuntos abordados, aconselhou os discentes sobre a importância dos estudos e contou a história do colégio, espaço doado pelos seus familiares. O escritor José Augusto Coppi também não pode comparecer ao colégio, por isso respondeu ao questionário por e-mail.

Mantendo as equipes, de forma coletiva, os alunos fizeram a primeira produção. A correção foi primeiro feita de forma coletiva pelos alunos, cada equipe corrigiu o texto da outra equipe, a partir de uma tabela oferecida no caderno pedagógico. Depois a professora fez uma correção considerando todos os conteúdos trabalhos em sala. Vale destacar que a primeira produção serviu de base para que a professora avaliasse as dificuldades e elaborasse novas atividades específicas para o ensino e aprendizagem, por exemplo, de conteúdos como o emprego da terceira pessoa do discurso na organização do texto, cronologia dos fatos relatados, paragrafação, pontuação, entre outros pontos.

Na sequência, os alunos receberem a primeira produção de volta, com as devidas correções mencionadas, e, com o auxílio da professora, os textos foram revidados e reescritos para uma versão definitiva.

Por fim, a professora digitalizou as biografias e organizou a montagem do livro, com capa construída também pelos alunos. O livro com as biografias dos escritores de Jacarezinho foi lançado em evento no colégio e depois entregue para o acervo da biblioteca do colégio e da biblioteca do município. A seguir, transcrevemos uma biografia a título de exemplificação do trabalho realizado pelos alunos.

Biografia de José Augusto Coppi

O escritor José Augusto Coppi nasceu em Jacarezinho, em 14 de outubro de 1953, filho de Fermino Coppi e Emília Arcângelo Coppi. É casado há 41 anos com a senhora Maria Helena Mascaro Coppi; os dois têm três filhos, o mais velho chama-se Adriano, 39 anos; Ricardo, 35; e Marcelo, de 34 anos.

Coppi morou em Jacarezinho até 7 anos de idade, depois mudou-se para Ribeirão Claro, onde residiu até os 15 anos. Logo, passou a infância parte em Jacarezinho e a outra 
parte em Ribeirão Claro, onde estudou no Grupo Escolar Correia Defreitas e no Ginásio Estadual de Ribeirão Claro. Gostava de jogar futebol de salão, porém não era bom jogador. Segundo o escritor, muitas professoras e professores foram importantes em sua vida naquela época. Morou também em Santo Antônio da Platina, até os 21 anos. Ele e sua família retornaram a Jacarezinho e nessa cidade o escritor mora há 49 anos. Passou

Graduado em Direito, pela Faculdade Estadual de Direito do Norte Pioneiro, turma de 1977; e em Letras/Literatura pela Universidade Estadual do Norte Pioneiro (UENP), turma de 2009.

José Augusto foi bancário na maior parte de sua vida profissional, trabalhou nas agências do Banco do Brasil, de Jacarezinho e Juvevê, em Curitiba.

No terceiro ano do grupo escolar, aprendeu a fazer descrição e redação. Ele gostava de ler gibis e livros infantis. Gostava também de ouvir os causos que seu avô Nello, pai de sua mãe, narrava para os netos. Nessa fase, gostava de escrever cartas para suas irmãs casadas que não moravam em Ribeirão Claro. Apreciava a leitura de contos publicados em revistas. Tem lembranças do livro "Reinações de Narizinho", de Monteiro Lobato. Também gostava de ler "Os Miseráveis", de Victor Hugo.

$\mathrm{Na}$ adolescência, ficaram marcados os filmes, principalmente de bang-bang e de comédia, os quais assistia aos domingos, na matinê e também na sessão da noite; também gostava de ouvir rádio, preferencialmente os programas esportivos. Na fase adulta, ia ao cinema e quermesses. Foi quando começou a namorar sua esposa Maria Helena.

Sua inspiração para escrever, conforme conta Coppi, vem por acaso, vem de um sonho, de algo que vê quando está caminhando e/ou viajando, de uma cena de filme, de uma conversa, de uma recordação. Gosta de escrever contos por serem formados por poucos personagens e serem histórias curtas. Todos os dias ele escreve, reescreve, corrige, altera uma coisa aqui, outra ali.... Faz isso sem a obrigação de publicar. Escrever é um hobbie que preenche uma parte de suas manhãs. $O$ autor não consegue distinguir de qual de seus livros gosta mais.

Ele mesmo paga as edições de seus livros. Faz os lançamentos convidando seus amigos e conhecidos. A obra que ele mais vendeu foi "Os retirantes do Araçá".

Coppi gosta de vários autores, dentre eles: Lygia Fagundes Telles, Carlos Heitor Cony, Moacir Scliar, Rubem Fonseca, Marina Colassanti, Jorge Amado, Luiz Vilela, Luis Fernando Veríssimo, Zuenir Ventura, Machado de Assis e Lima Barreto. A sua autora preferida é a Lygia Fagundes Telles. Os passatempos prediletos dele são escrever, ler, navegar pela internet, ouvir rádio e assistir televisão. Está trabalhando num romance que se passa nos anos sessenta, numa cidade fictícia chamada Aldeia Nova.

Seus livros são direcionados ao público adulto, mas também podem ser lidos pelos jovens e adolescentes. Quando está escrevendo, mantém em segredo a sua história, somente quando sente que o trabalho está bom, que o mostra para sua esposa para que ela leia e opine. Para o escritor, os ingredientes que não podem faltar numa boa história são mistério, suspense e humor. Não imagina o tipo físico de seus personagens, não tem definido seus rostos, nem seus corpos, simplesmente dá-Ihes nomes.

José Antônio fez aulas de pintura óleo sobre tela e por isso tem um bom acervo de quadros. Vendeu alguns e deu outros aos familiares. Participou de salões de artes e sua obra "Frevo de rua" está retratada no Dicionário das Artes Plásticas no Paraná. Fica muito contente quando alguém vem lhe dizer que leu e gostou do que ele escreveu. Gosta de viajar com sua esposa Maria Helena. O destino preferido dos dois é Rio Quente, em Goiás, onde tem a praia do Cerrado com água morna e ondas artificiais.

Para o autor, escrever é um desafio, é uma forma de exteriorizar os sentimentos no coração, é uma forma de registrar os sentimentos. Mas para o escritor, deve-se escrever sempre com calma, sem receio de apagar, rasgar e começar de novo. É necessário praticar, é 
O gênero textual biografia como eixo organizador de uma proposta de intervenção didática na educação básica

uma tarefa contínua. Escrever exige cuidado para não registrar palavras e pensamentos desconexos. É preciso ler outros autores. Também ler e reler o que escreveu para evitar passar por ridículo. Deve-se ter em mente que a sua mensagem dificilmente será do agrado de todos.

Sua carreira literária teve início em primeiro de julho de 1999, com a publicação do conto Instante de uma vida, no jornal Hora $\mathrm{H}$, de circulação em Jacarezinho. Em março, de 2006, participou da XIX Bienal Internacional do Livro de São Paulo, com o lançamento do livro Câmera Indiscreta.

Para o escritor a sua paixão tanto em escrever como em ler proporciona-lhe momentos em que ele pode viajar, sonhar, amar, perdoar, constituindo-se num passatempo de enorme prazer.

\section{Obras}

Os retirantes do Araçá. Andirá: Gráfica e editora Godoy, 2000.

Alvorecer aos quarenta. Andirá: Gráfica e editora Godoy, 2001.

Contos de vanguarda. Andirá: Gráfica e editora Godoy, 2002.

Câmera indiscreta. Rio de Janeiro: Editora Litteris, 2006.

Encontros, desencontros e reencontros em minicontos. Andirá: Gráfica e editora Godoy, 2007.

Chá das cinco. Disponível em: http://www.usinadeletras.com.br/, 2012.

\section{Premiações}

IX Concurso Literário internacional da Academia de Ciências e Letras de Conselheiro Lafaiete (MG), em 2002, com o conto "Apenas um pequeno deslize".

IX Concurso de contos da ASES - Associação de escritores de Bragança Paulista (SP), em 2003, com o conto "A escolha".

III Concurso Nacional de Literatura Revelações do Terceiro Milênio de Caçu (GO), em 2005, com o conto "Uma caixa de lápis de cor". 


\title{
Considerações Finais
}

Após implementado o projeto de intervenção pedagógica, nossa primeira afirmativa é a de que os resultados das ações realizadas validam o que Baltar et al. (2005, p. 165) afirma sobre o trabalho com gêneros discursivos/textuais:

\begin{abstract}
Trata-se, $[\ldots]$, de um ensino dos textos a partir da análise de suas dimensões 'cotextual': composição infra-estrutural, modalidades discursivas predominantes, sequências textuais a serviço da textualização; e 'contextuais': os ambientes discursivos, os suportes textuais em que ocorrem as atividades de linguagem, o papel dos interlocutores na interação e a situação de enunciação. Essa compreensão de quais textos circulam na sociedade, de quais são suas características e quais seus efeitos na interação social entre os usuários da língua é condição sine qua non para que os professores, na sua atuação como mediadores dos trabalhos de leitura e releitura e de escrita e de reescrita desses textos, possam ajudar seus alunos a desenvolverem sua Competência Discursiva (BALTAR et al., 2005, p. 165 , grifo do autor).
\end{abstract}

A escolha pelo gênero biografia, entre outros motivos, para que a cultural literária da cidade de Jacarezinho pudesse ser conhecida pelos alunos e ser instrumento motivador do aprimoramento das práticas de leitura e de escrita, também pode ser destacada como positiva. A aproximação dos alunos com os escritores que contaram suas histórias de vida, as histórias contidas em suas obras, a paixão pela cidade de Jacarezinho e pelos lugares e acontecimentos que tornam o lugar uma inspiração para a produção de registros, contos, poemas despertou o interesse dos alunos para a leitura das obras dos autores jacarezinhenses, para a construção das entrevistas e para a produção textual.

Durante a etapa de implementação, tivemos alguns problemas para cumprir o planejado, como o atraso para o início dos trabalhos, alguns alunos faltosos que não acompanhavam a sequência das atividades, alguns dos nossos escritores tiveram problemas de saúde não podendo comparecer aos eventos como concebidos. Apesar de todos os percalços, a elaboração e a 
implementação do projeto de intervenção foi muito importante para o desenvolvimento das capacidades de linguagem dos alunos, o que foi notório na produção textual final.

Esperamos, com esse nosso relato de experiências, auxiliar outros professores da educação básica no processo de desenvolvimento de práticas de leitura e de produção textual de seus alunos.

\section{Referências}

BAKHTIN, Michail. Estética da criação verbal. Tradução de Paulo Bezerra. 4. ed. São Paulo: Martins Fontes, 2003.

BALTAR, Marcos; NARDI, Fabiele Stockmans; FERREIRA, Luciane Todeschini; GASTALDELLO, Maria Eugênnia. O interacionismo sociodiscursivo na formação dos professores: o perigo da gramaticalização dos gêneros textuais. Signum, Londrina, v. 1, n. 8, p. 159-172, 2005.

BARROS, Eliana Merlin Deganutti. Transposição didática externa: a modelização do gênero na pesquisa colaborativa. Raído, Dourados, v. 6, n. 11, p. 11-35, jan./jun. 2012.

BRASIL. Ministério da Educação do Desporto. Parâmetros curriculares nacionais. língua portuguesa: ensino fundamental. Brasília: MEC, 1997.

DOLZ, Joaquim; NOVERRAZ, Michèle; SCHNEUWLY, Bernard. Sequência didáticas para o oral e a escrita: apresentação de um procedimento. In: SCHNEUWLY, Bernard; DOLZ, Joaquim. Gêneros orais e escritos na escola. Tradução de Roxane Rojo e Glaís Sales Cordeiro. Campinas, SP: Mercado de Letras, 2004. Campinas, SP: Mercado das Letras, 2004. p. 95-128.

DOLZ, Joaquim; SCHNEUWLY, Bernard. Gêneros orais e escritos na escola. Tradução e organização de Roxane Rojo e Glaís Sales Cordeiro. Campinas, SP: Mercado de Letras, 2004.

FRAZÃO, Dilva. Monteiro Lobato: escritor brasileiro. Disponível em: https://www.ebiografia.com/monteiro_lobato/. Acesso em: 25 jun. 2019.

LUIS Fernando Veríssimo: escritor e humorista brasileiro. UOL, São Paulo, 2005. Disponível em: https://educacao.uol.com.br/biografias/luis-fernandoverissimo.htm. Acesso em: 25 jun. 2019. 
MARECO, Raquel Tiemi Masuda; ALFENA, Gelise. Biografia: da construção de um modelo didático às capacidades de linguagem ensináveis em sala de aula. Revista Trama, Marechal Cândido Rondon, v. 8, n. 16, p. 75-96, 2. sem. 2012.

MARIO Quintana. Sua pesquisa. Disponível em:

https://www.suapesquisa.com/biografias/mario_quintana.htm. Acesso em: 25 jun. 2019.

MOREIRA, Daniele Fernanda Feliz. Pedro Bandeira. Info Escola, 2017.

Disponível em: https://www.infoescola.com/biografias/pedro-bandeira/. Acesso em: 25 jun. 2019.

PARANÁ. Secretaria de Estado da Educação. Diretrizes curriculares da rede pública de educação básica do Estado do Paraná: língua portuguesa. Curitiba: SEE, 2008.

PINTO, Margarida Paulino de Cerqueira. Biografia: desenvolvimento das capacidades de linguagem dos alunos da educação básica e disseminação da cultura local. In: PARANÁ. Secretaria de Estado da Educação. Os desafios da escola pública paranaense na perspectiva do professor PDE: produções didático-pedagógicas. Curitiba: SEE, 2016. (Cadernos PDE, n. 2).

ROJO, Roxane; BARBOSA, Jaqueline P. Hipermodernidade, multiletramentos e gêneros discursivos. São Paulo: Parábola, 2015.

ZIRALDO: jornalista, teatrólogo, chargista, caricaturista e escritor. UOL, São Paulo, 2005. Disponível em: https://educacao.uol.com.br/biografias/ziraldo.htm. Acesso em: 25 jun. 2019. 